\title{
Practical equivalence of laboratory and field measurements of gut passage time in two penaeid shrimp species
}

\author{
J. J. Beseres ${ }^{1, *}$, A. L. Lawrence ${ }^{2}$, R. J. Feller ${ }^{3}$ \\ ${ }^{1}$ Marine Science Program, Baruch Marine Field Laboratory, University of South Carolina, PO Box 1630, Georgetown, \\ South Carolina 29442, USA \\ ${ }^{2}$ Shrimp Mariculture Project, Texas Agricultural Experiment Station, Texas A\&M University, 1300 Port Street, \\ Port Aransas, Texas 78373, USA
}

${ }^{3}$ Department of Biological Sciences, Marine Science Program, University of South Carolina, Columbia, South Carolina 29208, USA

\begin{abstract}
Gut passage times (GPTs) of 2 species of juvenile penaeid shrimp Farfantepenaeus aztecus (Pèrez Farfante \& Kensley, 1997) and Litopenaeus vannamei (Pèrez Farfante \& Kensley, 1997) were measured in field and laboratory feeding trials using soy-based feeds varying in percent dry weight of either fiber (2.3 to $11.3 \%$ ), protein ( 20.1 to $45 \%$ ), or lipid (3.5 to $13.5 \%$ ). To trace feed movement visually through the gut, feeds were thoroughly mixed with inert fluorescent latex beads. Because it was not possible to continuously view feed passage through the shrimp guts in the field trials (as is possible in the laboratory), we developed indirect methods that allowed us to obtain periodic 'snapshots' of feed movement through shrimp guts at 10 min intervals, which were then compared with direct observations of feed movement used in the laboratory trials and used to calculate GPT and gut passage rate. Indirect methods underestimated GPTs in field feeding trials, necessitating their adjustment before comparison with the directly measured laboratory GPTs. Overall, mean GPTs for $L$. vannamei fed 13 different fiber, protein, and lipid feeds were not significantly different between laboratory and field feeding trials. In general, mean laboratory GPTs for $L$. vannamei were slightly shorter than mean GPTs from field feeding trials (1 to $20 \mathrm{~min}$ ). Utilizing only 1 feed (base feed: $30.1 \%$ protein, $5.3 \%$ fiber, $7.5 \%$ lipid), mean GPTs of $F$. aztecus in laboratory feeding trials were again slightly shorter (12 min) than mean field GPTs. We suggest that a temporal change in mean GPT of 1 to 20 min for shrimp fed the same feed in laboratory and field settings may be trivial enough to justify use of simpler laboratory measurements to extrapolate the GPTs of field populations for design of more efficient feeding regimes.
\end{abstract}

KEY WORDS: Gut passage time - Soy-based feed $\cdot$ Feeding $\cdot$ Nutrition $\cdot$ Farfantepenaeus aztecus · Litopenaeus vannamei

Resale or republication not permitted without written consent of the publisher

\section{INTRODUCTION}

While descriptive field studies of marine and estuarine faunal feeding are performed routinely, in situ measurements of dynamic feeding parameters are more difficult to obtain. Research aimed at understanding feeding dynamics, such as ingestion and defecation rates, gut passage time (GPT), assimilation efficiency, and feeding periodicity through controlled experiments have thus generally been conducted in the laboratory (Evjemo et al. 2000, Wu et al. 2002, Bol- lens \& Penry 2003, Harvey \& Morrier 2003, Wuenschel \& Werner 2004). An untested assumption in most of these studies is that the feeding responses measured under laboratory conditions are representative of those that occur naturally in the field. Much needed fieldbased comparisons, such as those provided for a coastal copepod by Tiselius et al. (1995) and for grass shrimp by Gregg \& Fleeger (1998), are scarce.

As intensive production of penaeid shrimp increases globally, so does the necessity for management practices focused on maintaining high water 
quality. Both over-application and subsequent accumulation of artificial feeds in sediments have been implicated as causative factors for poor water quality (Kanazawa 1997, Lawrence \& Lee 1997, Allan \& Smith 1998, Nunes \& Parsons 1998). Measurements of shrimp GPTs are thus highly relevant to the maintenance of water quality-slower GPTs provide more opportunities for the gut lining to absorb nutrients from the feed before defecation, while faster GPTs result in defecation of foods that have been incompletely processed in the gut (Taghon 1981, Relyea \& Auld 2004). Faster GPTs can lead to water quality degradation due to accumulation of undigested foods in shrimp pond sediments. In order to maintain water quality for intensive shrimp production and reduced incidence of disease, it is useful to have reliable in situ field measurements of shrimp feeding dynamics. We conducted experiments to test whether measurements of GPTs for 2 species of penaeid shrimp were similar in laboratory and field settings. If so, this would help validate the assumption that laboratoryderived measurements are representative of field reality.

Our knowledge of the basic mechanisms controlling gut passage dynamics for penaeid shrimp is variable and incomplete (Lee 1971, Sedgwick 1979, Fair et al. 1980, Koshio et al. 1993, Glencross et al. 2002). Results from previous laboratory feeding trials showed that GPTs of juvenile Farfantepenaeus aztecus, Litopenaeus setiferus, and Litopenaeus vannamei were similar within species when consuming foods of varying quality (Stephen 2001, Beseres et al. 2005). Our null hypothesis presumed that shrimp GPTs would be similar between laboratory and field feeding trials using identical feeds varying in levels of fiber, protein, and lipid content. Alternatively, we hypothesized that shrimp in field feeding trials will have faster GPTs due to consumption of detritus, diluting the nutritional quality of the experimental feeds and reducing absorption time by the gut lining. However, should shrimp GPTs be similar between feeding trial settings, estimates of GPTs in laboratory feeding trials could be extrapolated reliably to field populations of the same species.

\section{MATERIALS AND METHODS}

This study was conducted to compare results with previous research examining the effects of variations in food quality on GPT and nitrogen assimilation efficiency in juvenile white shrimp, Litopenaeus setiferus, in the laboratory (Stephen 2001). Using many of the same feeds as Stephen (2001), we measured GPTs of 2 other species of shrimp in a field setting, either in a natural tidal creek (juvenile brown shrimp, Farfantepenaeus aztecus) or in a commercial shrimp pond (juvenile Pacific white shrimp, Litopenaeus vannamei). We tested whether GPTs measured indirectly in a field setting were similar to direct measurements of GPT in a laboratory setting. While previous studies of GPTs under controlled laboratory conditions have been necessary for comparing feed formulations, development and utilization of more natural experimental systems is recommended and desirable (Lawrence \& Lee 1997). We utilized an inert tracer method for shrimp in tidal creek and pond habitats to provide quantitative in situ field estimates of shrimp GPTs.

Shrimp collection and holding conditions for field feeding trials. Juvenile Farfantepenaeus aztecus were collected from Oyster Landing and Bly tidal creeks at the Baruch Marine Field Laboratory in Georgetown,

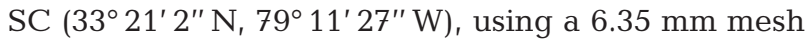
seine net. Juvenile Litopenaeus vannamei were collected with a $6.35 \mathrm{~mm}$ mesh cast net from shrimp ponds in Beaufort $\left(32^{\circ} 22^{\prime} 24^{\prime \prime} \mathrm{N}, 80^{\circ} 45^{\prime} 00^{\prime \prime} \mathrm{W}\right)$ and Charleston $\left(32^{\circ} 37^{\prime} 24^{\prime \prime} \mathrm{N}, 80^{\circ} 52^{\prime} 30^{\prime \prime} \mathrm{W}\right), \mathrm{SC}$, managed by the Palmetto Aquaculture Company (Columbia, SC). F. aztecus were collected in the early spring of 2001, and L. vannamei collections took place throughout the summer and fall of 2001. F. aztecus individuals were held for an average of $2 \mathrm{~d}$ in continuously circulating seawater tanks (diameter $1.5 \mathrm{~m}$ and water depth $0.75 \mathrm{~m}$ ) and fed the base feed (Table 1) ad libitum in the morning and evening. L. vannamei were used immediately after collection from the pond, and were returned live directly to the pond after each trial.

Feed preparation. Thirteen soy-based feeds with varying proportions (\% dry weight) of fiber, protein, and lipid were developed at the Texas Agricultural Ex-

Table 1. Ingredients and composition (\% dry wt) of 13 soy-based feeds offered to 2 species of penaeid shrimp in field and laboratory feeding trials

\begin{tabular}{|c|c|c|c|c|c|c|c|c|c|c|c|c|c|}
\hline \multirow{2}{*}{ Ingredients } & \multirow{2}{*}{$\begin{array}{l}\text { Base } \\
\text { feed }\end{array}$} & \multicolumn{4}{|c|}{ Fiber } & \multicolumn{4}{|c|}{ — Protein } & \multirow{2}{*}{ Low } & \multicolumn{2}{|c|}{ Lipid } & \multirow[b]{2}{*}{ High } \\
\hline & & Low & $\begin{array}{l}\text { Med } \\
\text { low }\end{array}$ & $\begin{array}{l}\text { Med } \\
\text { high }\end{array}$ & High & Low & $\begin{array}{c}\text { Med } \\
\text { low }\end{array}$ & $\begin{array}{l}\text { Med } \\
\text { high }\end{array}$ & High & & $\begin{array}{c}\text { Med } \\
\text { low }\end{array}$ & $\begin{array}{l}\text { Med } \\
\text { high }\end{array}$ & \\
\hline Total protein & 30.1 & 30.1 & 30.1 & 30.1 & 30.1 & 20.1 & 25.1 & 37.0 & 45.0 & 30.1 & 30.1 & 30.1 & 30.1 \\
\hline Total fiber & 5.3 & 2.3 & 3.8 & 7.8 & 11.3 & 5.3 & 5.3 & 5.3 & 5.3 & 5.3 & 5.3 & 5.3 & 5.3 \\
\hline Total lipid & 7.5 & 7.5 & 7.5 & 7.5 & 7.5 & 7.5 & 7.5 & 7.5 & 7.5 & 3.5 & 5.5 & 10.0 & 13.5 \\
\hline
\end{tabular}


periment Station (Table 1). The feeds were formulated so that 2 of the 3 variable feed component levels (fiber, protein, or lipid) were held constant, while levels of the third component ranged from low to high. To ensure their positive identification in the shrimp's digestive tract and to trace their movements through the gut, the feeds were mixed with inert fluorescent latex beads ( 2 to $5 \mu \mathrm{m}$ diameter, Radiant Color) before pelleting (Hoyt et al. 2000, Ahrens et al. 2001). The labeled feeds were then combined with seawater (19 $\mathrm{g}$ feed:0.03 $\mathrm{g}$ fluorescent beads:10 ml seawater) to form a paste, extruded through a pastry bag, cut into pellets ( $5 \mathrm{~mm}$ diameter), and frozen for use in the feeding trials. Although the extruded feeds did not contain a binder, feed pellets remained intact during and after completion of the feeding trial. Feeds were identified by number rather than by content in order to disguise their provenance.

Tidal creek feeding trials. Field feeding trials were performed with juvenile brown shrimp Farfantepenaeus aztecus in Oyster Landing Creek (3321' $1^{\prime \prime} \mathrm{N}$, $79^{\circ} 11^{\prime} 2^{\prime \prime}$ W) from May to August 2001 during daytime low tides. Enclosures of dimensions $30 \times 30 \times 10 \mathrm{~cm}$ were crafted of $1.27 \mathrm{~cm}$ PVC and 2 layers of polyethylene mesh (inner layer $0.47 \mathrm{~cm}$ mesh, outer layer $0.64 \mathrm{~cm}$ mesh) to prevent predator (fish, crabs, etc.) entry. The bottom of the enclosures was covered with only a single layer of $0.64 \mathrm{~cm}$ mesh to allow shrimp contact with the sediment for benthic feeding. Preliminary laboratory observations (10 shrimp inside enclosures placed in a seawater-filled swimming pool) confirmed shrimp feeding behavior was similar to feeding behavior observed directly in the laboratory feeding experiments using transparent, round aquaria and non-turbid seawater (continuous, uninterrupted ingestion while grasping feed and using the pereiopods to transfer particles to the mouthparts).

To conduct the field feeding trials for Farfantepenaeus aztecus, 24 enclosures were separated into 2 replicate sets of 12. A total of 240 shrimp of total length (TL, measurement from tip of rostrum to tip of telson) $52.7 \pm$ $1.0 \mathrm{~mm}$ (mean $\pm \mathrm{SE}$ ) were randomly selected from the holding tanks, transported $0.3 \mathrm{~km}$ in aerated $45.5 \mathrm{l} \mathrm{cool-}$ ers, and placed with 10 shrimp per enclosure in the creek. The enclosures were staggered along the main creek axis (mean water depth $\sim 1 \mathrm{~m}$ ) 1 $\mathrm{m}$ apart, with the 2 sets of enclosures separated by approximately $15 \mathrm{~m}$. Following a 10 min acclimation period, 10 frozen feed pellets were administered over a $1 \mathrm{~min}$ period to all 24 enclosures. The feeding trial began $\left(t_{0}\right)$ once all the enclosures were supplied with feed. Surface salinity and water temperature were then measured.

At intervals of $10 \mathrm{~min}$ throughout the $120 \mathrm{~min}$ trial, 1 enclosure from the downstream end of each replicate set was retrieved (2 total). Shrimp were immediately removed from the enclosures and placed in plastic bags submerged in crushed ice, halting feed passage through the gut (Beseres et al. 2005). After completion of the field trial, shrimp were examined under a stereo-microscope to record the 'snapshot' of the feed location and any natural feed mass in the gut; shrimp TL was also measured.

Aquaculture pond feeding trials. The field feeding trials for Pacific white shrimp Litopenaeus vannamei occurred in tidally influenced shrimp ponds in Beaufort and Charleston, SC, from June to July 2001. The Beaufort pond (8.5 ha) had been stocked in February with 12 shrimp $\mathrm{m}^{-2}$, and the Charleston pond (3.0 ha), in March with $\sim 17$ shrimp $\mathrm{m}^{-2}$. Methods and experimental design used in the pond feeding trials were analogous to those in the creek feeding trials. The use of a starvation period prior to feeding is common practice with shrimp (Feller 1998, Nunes \& Parsons 2000b, Stephen 2001), and it would have been advantageous to starve the field shrimp as in the laboratory feeding trials; however, this was not possible. We intended for field and laboratory starvation methods to be similar, but the pond managers requested minimal handling, and thus we were unable to conduct a starvation period with the field shrimp.

Shrimp of TL $94.3 \pm 9.9 \mathrm{~mm}$ (mean $\pm \mathrm{SE}$ ) were collected nearby with cast nets and immediately used in the feeding trials. Preliminary laboratory feeding trials determined that Litopenaeus vannamei consistently required $<90$ min to achieve defecation; thus, 2 sets of 9 enclosures (18 total) were used (90 min trial period). The 'snapshot' of feed location in the gut was recorded on site using a stereo-microscope, immediately following each enclosure's removal at random from the pond (every 10 min after $t_{0}$ ). After examination and scoring, shrimp were measured (TL) and returned live to the pond.

Holding conditions for laboratory feeding trials. Litopenaeus vannamei and Farfantepenaeus aztecus of similar TL were collected with seines and cast nets from their field trial settings and transported for $3 \mathrm{~h}$ in aerated coolers to re-circulating seawater tanks in the Seawater Culture Facility at the University of South Carolina in Columbia, SC, for holding before use in the laboratory feeding trials. The 'Living Stream' recirculating seawater tank measured $205 \mathrm{~cm} \times 57 \mathrm{~cm} \times$ $20 \mathrm{~cm}$, and was divided into 5 sections, 3 for holding shrimp, and 2 end sections for water circulation and bio-filtration. A combination of filtered seawater and distilled water (salinity $27 \%$, temperature $22^{\circ} \mathrm{C}$ ) flowed continuously through each section. Shrimp were fed the base feed (Table 1) in the morning and evening, when salinity and temperature were monitored. Fifty percent of the water was drained and replaced with fresh, filtered seawater every $2 \mathrm{wk}$. Leftover feed and fecal matter was siphoned from the tanks daily. 
Laboratory feeding trials. Litopenaeus vannamei and Farfantepenaeus aztecus GPTs were measured in laboratory feeding trials. Trials with $L$. vannamei occurred between July and December 2001, and trials with F. aztecus during May 2002; both sets of feeding trials were conducted between 09:00 and 17:00 $\mathrm{h}$ in a fluorescent-lit laboratory at room temperature. The same feeds were used as in the field feeding trials.

Laboratory feeding trial methods were identical to those used by Stephen (2001). Prior to initiation of a feeding trial, 4 shrimp were randomly selected from a section of the holding tank and placed in pairs in each of 2 aerated, clear, round plastic aquaria $(25 \mathrm{~cm}$ diameter, $20 \mathrm{~cm}$ depth, 4 l filtered seawater [ 24 to $30 \%$ ] ]), and starved for 2 to $3 \mathrm{~h}$ to empty the gut of any previously consumed food. The guts of similarly sized juvenile Litopenaeus setiferus were visually empty after $2 \mathrm{~h}$ (Stephen 2001). The use of the fluorescent tracer allowed visual identification of experimental feed in the shrimp gut. A starvation period was used to standardize the laboratory conditions, to eliminate differential hunger, and to clear the gut of all other foods. Aeration was then removed (to eliminate disturbance), and several pieces of frozen pellets from a randomly selected feed were added to the aquaria and provided ad libitum throughout the trial. Time zero $\left(t_{0}\right)$ for each shrimp began when it first ingested feed.

The 2 pairs of shrimp were observed continuously from above for $120 \mathrm{~min}$, with the location of food in the gut recorded every $10 \mathrm{~min}$. Shrimp did not react to the physical presence or slight movements of the observer. Fecal strands were removed by pipette to prevent coprophagy. At the conclusion of the feeding trial (time of first defecation of labeled feed by each animal), shrimp TL was measured, and shrimp were placed into a separate compartment of the holding tank so as to not be available for another trial until several days later.

Determination of GPT. Shrimp GPT in laboratory feeding trials was observed directly without temporal error, and was defined as the time from first ingestion of labeled feed to its first defecation (to the nearest minute). Observers were readily able to visually identify the location of labeled feed in the gut while viewing shrimp from $0.3 \mathrm{~m}$ above the aquaria. Stephen (2001) performed CHN analysis of fecal strands, and showed that the fluorescent latex beads and feed did not segregate during gut passage, as fecal strands contained consistently well-mixed feed and latex bead components.

We could not directly observe shrimp in field feeding trials, thus we developed indirect GPT determination methods. Feed passage was recorded based on 'snapshots' of the location of the leading edge of the feed (closest to the anus). A score from 0 to 5 on an interval scale based on feed location was assigned to each shrimp $(0=$ no feed in any part of the gut, $1=$ labeled feed in the proventriculus, $2=$ labeled feed $1 / 4$ of the way though the intestine, $3=$ labeled feed $1 / 2$ way through the intestine, 4 $=$ labeled feed $3 / 4$ of the way through the intestine, $5=$ labeled feed at the anus). Mean field GPT was thus determined indirectly as a weighted average of all times when individual shrimp were recovered with a score of 5 across all 10 min enclosure recovery periods (Beseres et al. 2005) (Table 2a,b). This indirect method of observing 'snapshots' of feed location in the gut introduces a potential bias (overestimate) of GPT for each shrimp of up to $10 \mathrm{~min}$.

Longitudinal measurements. The endpoints for our field and laboratory determinations of GPT were different. In the laboratory, the endpoint of GPT was determined by the first defecation of labeled feed. In the field, a score of 5 (feed at the anus) was the endpoint of GPT based on 'snapshots' of feed location in the gut observed at 10 min intervals; defecation was not directly observed. In order to determine whether these 2 endpoints were actually the same moment in time, the 'defecation delay' (elapsed time between the labeled feed reaching the anus [score $=5$ ] and actual defecation) of 8 different shrimp for both species was measured. We were particularly interested in whether GPT and any time delay were constant for an individual shrimp fed the same feed type in several feeding trials spread over several weeks. Pairs of Litopenaeus vannamei and pairs of Farfantepenaeus aztecus were starved for 2 to $3 \mathrm{~h}$, and then fed the base feed ad libitum at room temperature in round aquaria ( 24 to $30 \%$ ), as described above. Following the field methods for indirect GPT determination, movement of feed through each shrimp's gut was recorded at the end of every $10 \mathrm{~min}$ period. Once labeled feed reached the anus (score $=5$ ), we used the laboratory method for direct GPT determination to measure the potential 'defecation delay'; each shrimp was then watched continuously until its first defecation event.

Determination of gut passage rate. Gut passage rates $\left(\mathrm{GPR}, \mathrm{mm} \mathrm{min}^{-1}\right)$ for field and laboratory feeding trials were calculated as GPR $=\mathrm{GL} \mathrm{GPT}^{-1}$, where GL (gut length, $\mathrm{mm}$ ) was calculated from empirical measurements as GL $=0.75 T L$ (Clark 2000).

Statistical analysis. All analyses were conducted at the $95 \%$ confidence level $(\alpha=0.05)$ using the SAS System for Windows V.8. GPTs were compared by feed between the field and laboratory settings using an analysis of covariance (ANCOVA) with shrimp TL as the covariate (to remove any variability in GPT possibly due to shrimp size). We began the analysis for each feed type using the full model:

$$
Y_{i j k}=\mu+\alpha_{i}+\beta_{j}+(\alpha \beta)_{i j}+\varepsilon_{i j k}
$$

where $Y_{i j k}$ is the $k t h$ GPT value for the $j$ th level of factor $\beta$ (shrimp TL) and the ith level of factor $\alpha$ (trial set- 
Table 2. Farfantepenaeus aztecus. Method used to determine uncorrected field gut passage times (GPT) of base feed during the tidal creek trial. (a) For each 10 min period in the 120 min trial, the number of shrimp with food in the gut (feeders) was recorded. Location of the leading edge of labeled feed (closest to anus) was recorded as follows: 0 : no feed in gut; 1 : feed in the proventriculus: 2: feed $1 / 4$ of the way though the intestine; $3: \frac{1}{2}$ the way through; $4: 3 / 4$ of the way through; and 5: at anus. (b) For shrimp with a score of 5, GPTs were assigned as the midpoint of the time period during which feed reached the anus, e.g. for time period 71 to $80 \mathrm{~min}$, shrimp with a score of 5 were assigned GPT $=75 \mathrm{~min}$. Total number of shrimp with score $5(\mathrm{~N})=51\left(\mathrm{GPT}_{\mathrm{u}}\right.$ : uncorrected mean GPT; $\mathrm{GPT}_{\mathrm{c}}$ : corrected mean GPT [ $=\mathrm{GPT}_{\mathrm{u}}+15.4$ min correction factor $]$ )

\begin{tabular}{|c|c|c|c|}
\hline $\begin{array}{l}\text { Time period } \\
(\min )\end{array}$ & $\begin{array}{l}\text { No. of feeders/ } \\
\text { no. of shrimp recovered }\end{array}$ & Score $(1-5)$ & $\begin{array}{l}\text { No. of shrimp } \\
\text { with score } 1-5\end{array}$ \\
\hline $0-10$ & 22 / 22 & $1,2,3,4,5$ & $14,2,3,1,2$ \\
\hline $11-20$ & $12 / 12$ & $1,2,3,4,5$ & $9,1,1,0,1$ \\
\hline $21-30$ & $18 / 18$ & $1,2,3,4,5$ & $12,0,1,3,2$ \\
\hline $31-40$ & $18 / 19$ & $1,2,3,4,5$ & $13,2,1,0,1$ \\
\hline $41-50$ & $20 / 21$ & $1,2,3,4,5$ & $13,1,1,2,3$ \\
\hline $51-60$ & $19 / 20$ & $1,2,3,4,5$ & $10,0,1,4,4$ \\
\hline $61-70$ & $20 / 20$ & $1,2,3,4,5$ & $7,1,0,4,8$ \\
\hline $71-80$ & $12 / 12$ & $1,2,3,4,5$ & $3,0,2,1,6$ \\
\hline $81-90$ & $14 / 16$ & $1,2,3,4,5$ & $9,0,0,0,5$ \\
\hline $91-100$ & $19 / 20$ & $1,2,3,4,5$ & $8,0,1,2,8$ \\
\hline 101-110 & $12 / 12$ & $1,2,3,4,5$ & $5,0,1,2,4$ \\
\hline $111-120$ & $20 / 20$ & $1,2,3,4,5$ & $11,0,2,0,7$ \\
\hline \multicolumn{4}{|c|}{ (b) Calculation of GPT based on data in (a) } \\
\hline $\begin{array}{l}\text { Time period } \\
(\mathrm{min})\end{array}$ & $\begin{array}{c}\text { Gut passage time } \\
(x, \min )\end{array}$ & $\begin{array}{l}\text { No. shrimp with } \\
\text { score }=5(y)\end{array}$ & $\begin{array}{l}\text { Mean } \mathrm{GPT}_{\mathrm{u}}= \\
\Sigma[(x \times y) / \mathrm{N}]\end{array}$ \\
\hline $0-10$ & 5 & 2 & 0.2 \\
\hline $11-20$ & 15 & 1 & 0.3 \\
\hline $21-30$ & 25 & 2 & 1.0 \\
\hline $31-40$ & 35 & 1 & 0.7 \\
\hline $41-50$ & 45 & 3 & 2.6 \\
\hline $51-60$ & 55 & 4 & 4.3 \\
\hline $61-70$ & 65 & 8 & 10.2 \\
\hline $71-80$ & 75 & 6 & 8.8 \\
\hline $81-90$ & 85 & 5 & 8.3 \\
\hline 91-100 & 95 & 8 & 14.9 \\
\hline 101-110 & 105 & 4 & 8.2 \\
\hline $111-120$ & 115 & $\begin{array}{c}7 \\
N=51\end{array}$ & $\begin{array}{c}15.8 \\
\mathrm{GPT}_{\mathrm{u}}=75.4 \mathrm{~min} \\
\text { and } \mathrm{GPT}_{\mathrm{c}}=90.8 \mathrm{~min}\end{array}$ \\
\hline
\end{tabular}

$y_{0}+a x^{-1}$, where $y$ is $\operatorname{GPR}\left(\mathrm{mm} \mathrm{min}^{-1}\right)$, $x$ is GPT (min), and $y_{0}$ is the intercept for GPR when GPT $=0$.

\section{RESULTS}

\section{Farfantepenaeus aztecus and Litope- naeus vannamei: longitudinal mea- surements on individuals}

Repeated feeding trials used 8 individual shrimp (4 experiments shrimp ${ }^{-1}$, $\mathrm{N}=32$ observations) to measure any 'defecation delay' between feed reaching the anus and the time of actual defecation, which would cause an underestimation of GPT using our indirect field method (Table 3a,b). Delays of $15.4 \pm 1.8 \mathrm{~min}$ for $F$. aztecus and $16.9 \pm 3.3 \mathrm{~min}$ (mean $\pm \mathrm{SE}$ ) for $L$. vannamei were found when using the indirect field method as compared to direct laboratory observations. These mean correction factors were added to all field GPT measurements prior to creation of graphs and comparative statistical tests.

\section{Farfantepenaeus aztecus: field (tidal creek) and laboratory GPT}

F. aztecus GPTs from laboratory and field feeding trials were compared using the base feed only (Table 1), due to logistical constraints (shrimp had moved out of creeks, discontinuing further laboratory trials). There was a statistically significant difference $(\mathrm{p}=$ 0.038) in mean GPT between the corrected field $(\mathrm{N}=28)$ and laboratory

ting), and is the sum of the following 5 components: $\mu$ : grand mean (GPT); $\alpha_{i}$ : main effect of trial setting, field or laboratory; $\beta_{j}$ : main effect of shrimp (TL); $\alpha \beta_{i j}$ : interaction of trial setting $\times \operatorname{shrimp}(\mathrm{TL})$; and $\varepsilon_{i j k}$ : error term. If the full model showed no interaction effects, the model was then reduced to the parallel lines model:

$$
Y_{i j k}=\mu+\alpha_{i}+\beta_{j}+\varepsilon_{i j k}
$$

to test for differences in mean GPTs between the laboratory and field settings. Measurements of GPR were regressed against GPT measurements using best-fit inverse first-order regressions of the form $y=$
$(\mathrm{N}=51)$ trials, with mean laboratory GPT $\sim 12 \mathrm{~min}$ shorter than mean field GPT (Table 4). GPTs were not affected by differences in shrimp TL.

\section{Litopenaeus vannamei: feed fiber content-effect on field (shrimp pond) and laboratory GPT}

The effect of varying fiber percentage on GPTs in field and laboratory feeding trials was examined for L. vannamei using 5 feeds ranging from 2.3 to $11.3 \%$ fiber (Fig. 1a). Mean GPTs ( \pm SE) from the laboratory trials $(\mathrm{N}=141)$ and corrected means from field trials 
Table 3. Farfantepenaeus aztecus and Litopenaeus vannamei. Gut passage time (GPT) and lag time (defecation delay [in minutes]) results from longitudinal measurements on 16 individual shrimp (8 from each species) to determine any time delay between feed reaching the anus and actual defecation. GPTs were measured to the nearest minute, $\mathrm{N}=32$ observations for each species: (a) F. aztecus and (b) L. vannamei. Means of means shown in bold; n.a.: shrimp did not defecate during feeding trial

\begin{tabular}{|c|c|c|c|c|c|c|c|c|c|c|c|}
\hline \multicolumn{12}{|c|}{ (a) Farfantepenaeus aztecus (in 2002) } \\
\hline \multirow{2}{*}{$\begin{array}{l}\text { Shrimp } \\
\text { ID }\end{array}$} & \multirow{2}{*}{$\begin{array}{c}\mathrm{TL} \\
(\mathrm{mm})\end{array}$} & \multicolumn{2}{|c|}{ May 4-6 } & \multicolumn{2}{|c|}{ May 7-8 } & \multicolumn{2}{|c|}{ May 9-14 } & \multicolumn{2}{|c|}{ May 15-16 } & \multicolumn{2}{|c|}{ Mean $\pm 95 \%$ CI } \\
\hline & & GPT & Lag & GPT & Lag & GPT & Lag & GPT & Lag & GPT & Lag \\
\hline A1 & 42 & 103 & 37 & n.a. & - & 75 & 15 & 77 & 7 & $85.0 \pm 17.7$ & $19.7 \pm 17.6$ \\
\hline $\mathrm{A} 2$ & 56 & 98 & 28 & n.a. & - & 95 & 15 & 72 & 11 & $88.3 \pm 16.1$ & $18.0 \pm 10.1$ \\
\hline B1 & 44 & n.a. & - & 81 & 11 & 77 & 17 & 81 & 21 & $79.7 \pm 2.6$ & $16.3 \pm 5.7$ \\
\hline B2 & 58 & n.a. & - & 71 & 11 & 95 & 15 & 65 & 19 & $77.0 \pm 18.0$ & $15.0 \pm 4.5$ \\
\hline $\mathrm{C} 1$ & 46 & 63 & 21 & 84 & 14 & 63 & 3 & 98 & 14 & $77.0 \pm 16.8$ & $13.0 \pm 7.3$ \\
\hline $\mathrm{C} 2$ & 53 & 46 & 0 & 76 & 6 & 57 & 27 & 98 & 18 & $69.3 \pm 22.4$ & $12.8 \pm 11.9$ \\
\hline D1 & 45 & 64 & 4 & 92 & 12 & 59 & 9 & 107 & 27 & $80.5 \pm 22.4$ & $13.0 \pm 9.7$ \\
\hline \multirow[t]{2}{*}{ D2 } & 51 & 72 & 12 & 89 & 29 & 72 & 12 & 77 & 17 & $77.5 \pm 7.9$ & $17.5 \pm 7.9$ \\
\hline & & & & & & & & & & $79.3 \pm 4.0$ & $15.7 \pm 1.8$ \\
\hline \multicolumn{12}{|c|}{ (b) Litopenaeus vannamei (in 2001) } \\
\hline Shrimp & TL & \multicolumn{2}{|c|}{ Sep 5-13 } & \multicolumn{2}{|c|}{ Sep $19-27$} & \multicolumn{2}{|c|}{ Oct $10-30$} & \multicolumn{2}{|c|}{ Nov $13-14$} & \multicolumn{2}{|c|}{ Mean $\pm 95 \%$ CI } \\
\hline ID & $(\mathrm{mm})$ & GPT & Lag & GPT & Lag & GPT & Lag & GPT & Lag & GPT & Lag \\
\hline E1 & 90 & 86 & 16 & 119 & 19 & 84 & 4 & 83 & 33 & $93.0 \pm 17.0$ & $18.0 \pm 11.7$ \\
\hline E2 & 107 & 67 & 7 & 120 & 30 & 95 & 5 & 96 & 36 & $94.5 \pm 21.2$ & $19.5 \pm 15.5$ \\
\hline F1 & 92 & 81 & 21 & 70 & 0 & 93 & 43 & n.a. & - & $81.3 \pm 13.0$ & $21.3 \pm 24.3$ \\
\hline $\mathrm{F} 2$ & 108 & 75 & 15 & 87 & 7 & 90 & 40 & n.a. & - & $84.0 \pm 9.0$ & $20.7 \pm 19.5$ \\
\hline G1 & 86 & 99 & 39 & 57 & 7 & 74 & 14 & n.a. & - & $76.7 \pm 23.9$ & $20.0 \pm 19.0$ \\
\hline $\mathrm{G} 2$ & 99 & 88 & 18 & 70 & 10 & 94 & 4 & n.a. & - & $84.0 \pm 14.1$ & $10.7 \pm 7.9$ \\
\hline H1 & 86 & 120 & 10 & 67 & 7 & 83 & 13 & 74 & 4 & $86.0 \pm 23.1$ & $8.5 \pm 3.8$ \\
\hline \multirow[t]{2}{*}{$\mathrm{H} 2$} & 105 & 120 & 20 & 75 & 15 & 90 & 20 & 91 & 11 & $94.0 \pm 18.4$ & $16.5 \pm 4.3$ \\
\hline & & & & & & & & & & $86.7 \pm 4.5$ & $16.9 \pm 3.3$ \\
\hline
\end{tabular}

$(\mathrm{N}=302)$ are shown in Table 4. Shrimp fed the lowest $(2.3 \%)$ fiber feed showed significant differences in GPTs between field and laboratory $(\mathrm{p}=$ 0.013), with mean laboratory GPT $\sim 10$ min shorter than mean field GPT. Due to a significant interaction between shrimp TL and trial setting for the $7.8 \%(\mathrm{p}$ $=0.007)$ and $11.3 \%(p=0.079)$ fiber feeds, we could not interpret any differences between main effects on GPT for these feeds. Despite this statistically significant interaction, Fig. 1a suggests that mean GPTs in the field and laboratory for the $11.3 \%$ fiber feed

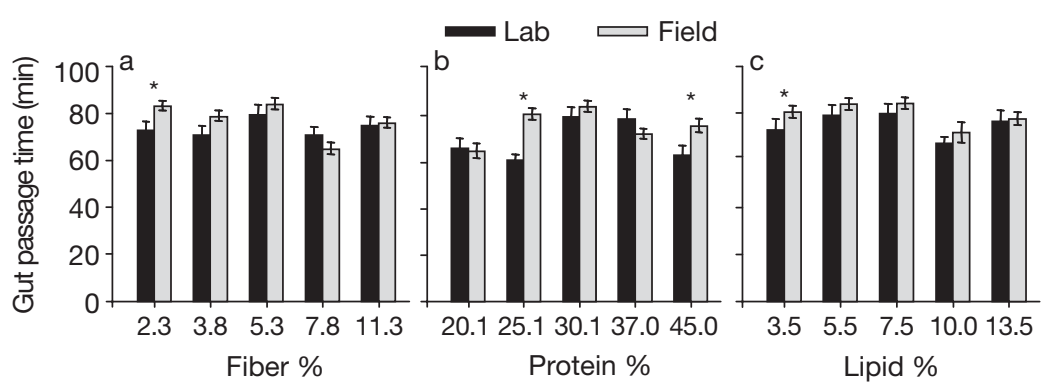

Fig. 1. Litopenaeus vannamei. Mean gut passage time (GPT) on feeds with varying (a) fiber ( $\mathrm{N}=141$ laboratory, 302 field), (b) protein $(\mathrm{N}=139$ laboratory, 283 field), or (c) lipid ( $\mathrm{N}=135$ laboratory, 192 field) content. Asterisks indicate significant differences ( $\alpha=0.05$ level) in mean GPTs between laboratory and field feeding trials, error bars $\pm 1 \mathrm{SE}$ were not different. Shrimp fed the 2.3, 3.8 and $5.3 \%$ fiber feeds had GPTs that were not affected by differences in shrimp TL.

\section{Litopenaeus vannamei: feed protein content-effect on field and laboratory GPT}

The effect of varying protein percentage on GPTs in field and laboratory feeding trials was also examined for L. vannamei using 5 feeds ranging from 20.1 to $45.0 \%$ protein (Fig. 1b). Mean GPTs $( \pm \mathrm{SE})$ from the laboratory trials $(\mathrm{N}=$ 139) and field trials $(\mathrm{N}=283)$ are shown in Table 4 . Shrimp fed the $25.1 \%$ protein feed $(p<0.001)$, and the $45 \%$ protein feed $(p=0.045)$ showed significant differences in GPTs between the field and laboratory trials. For these 2 feeds, mean GPTs in laboratory trials were shorter (by $\sim 20$ and $13 \mathrm{~min}$, respectively) than in field trials. GPT was significantly affected by shrimp TL for the 37 and $45 \%$ feeding trials, where TLs were significantly smaller in the laboratory feeding trials for the $37 \%$ protein 
Table 4. Farfantepenaeus aztecus and Litopenaeus vannamei. Mean total length and mean gut passage time (GPT) for field (corrected mean) and laboratory feeding trials with juvenile $F$. aztecus and $L$. vannamei on 13 feeds varying in levels of fiber, protein, or lipid (\% dry wt). Only the base feed (mid-level feed of fiber, protein, and lipid feed types) was used for F. aztecus. The other 12 feeds differed in composition from the base feed only in terms of 1 component (fiber, protein, or lipid), while the other 2 components were unchanged. Field GPTs were measured indirectly, and thus have been corrected for 'defecation delay' by the addition of 15.4 min for F. aztecus and 16.9 min for L. vannamei. Laboratory GPT results were measured directly, and thus are uncorrected

\begin{tabular}{|c|c|c|c|c|c|c|c|c|c|c|}
\hline \multirow[b]{2}{*}{$\begin{array}{l}\text { Feeds } \\
\text { (\% dry wt) }\end{array}$} & \multirow[b]{2}{*}{$\mathrm{N}$} & \multirow[b]{2}{*}{$\begin{array}{l}\text { Mean TL } \\
(\mathrm{mm})\end{array}$} & \multirow[b]{2}{*}{$\pm \mathrm{SE}$} & \multirow{2}{*}{$\begin{array}{l}\text { Field } \\
\text { Corrected mean } \\
\text { GPT (min) }\end{array}$} & \multirow{2}{*}{$\overline{ \pm \mathrm{SE}}$} & \multirow[b]{2}{*}{$\mathrm{N}$} & \multirow[b]{2}{*}{$\begin{array}{l}\text { Mean TL } \\
(\mathrm{mm})\end{array}$} & \multicolumn{2}{|c|}{ Laboratory } & \multirow[b]{2}{*}{$\pm \mathrm{SE}$} \\
\hline & & & & & & & & $\pm \mathrm{SE}$ & $\begin{array}{l}\text { Mean GPT } \\
\text { (min) }\end{array}$ & \\
\hline \multicolumn{11}{|l|}{ F. aztecus } \\
\hline Base feed $^{\mathrm{a}}$ & 51 & 47.9 & 1.6 & 90.8 & 4.1 & 28 & 49.3 & 1.1 & 78.7 & 2.9 \\
\hline \multicolumn{11}{|l|}{ L. vannamei } \\
\hline \multicolumn{11}{|l|}{ Fiber feeds } \\
\hline 2.3 & 44 & 89.7 & 1.1 & 83.2 & 2.1 & 29 & 101.0 & 1.9 & 73.1 & 3.3 \\
\hline 3.8 & 60 & 96.8 & 0.8 & 79.0 & 2.1 & 24 & 99.2 & 2.2 & 71.1 & 3.5 \\
\hline 5.3 & 25 & 95.2 & 2.1 & 84.1 & 2.5 & 30 & 96.2 & 2.3 & 79.7 & 4.0 \\
\hline 7.8 & 108 & 87.0 & 0.8 & 65.0 & 2.5 & 29 & 98.3 & 2.0 & 71.1 & 3.1 \\
\hline 11.3 & 65 & 90.7 & 1.1 & 76.2 & 2.2 & 29 & 98.4 & 1.8 & 75.2 & 3.5 \\
\hline \multicolumn{11}{|c|}{ Protein feeds } \\
\hline 20.1 & 62 & 101.2 & 1.0 & 64.9 & 3.2 & 26 & 95.0 & 2.1 & 66.0 & 4.3 \\
\hline 25.1 & 55 & 90.2 & 1.3 & 80.8 & 2.5 & 25 & 99.2 & 2.2 & 61.0 & 2.3 \\
\hline 30.1 & 25 & 95.2 & 2.1 & 84.1 & 2.5 & 30 & 96.2 & 2.3 & 79.7 & 4.0 \\
\hline 37.0 & 97 & 90.8 & 0.8 & 72.3 & 2.2 & 29 & 101.4 & 2.1 & 78.8 & 4.0 \\
\hline 45.0 & 44 & 103.8 & 1.2 & 75.8 & 2.9 & 29 & 100.1 & 1.7 & 63.3 & 3.8 \\
\hline \multicolumn{11}{|l|}{ Lipid feeds } \\
\hline 3.5 & 45 & 91.2 & 1.2 & 80.4 & 2.6 & 26 & 102.3 & 1.9 & 72.9 & 4.4 \\
\hline 5.5 & 40 & 101.2 & 1.0 & 83.7 & 2.6 & 23 & 101.6 & 1.9 & 79.0 & 4.4 \\
\hline 7.5 & 25 & 95.2 & 2.1 & 84.1 & 2.5 & 30 & 96.2 & 2.3 & 79.7 & 4.0 \\
\hline 10.0 & 32 & 99.8 & 1.9 & 71.7 & 4.4 & 31 & 97.4 & 1.4 & 67.1 & 2.8 \\
\hline 13.5 & 50 & 90.4 & 1.2 & 77.5 & 2.7 & 25 & 97.1 & 1.7 & 76.6 & 4.4 \\
\hline
\end{tabular}

feed $(\mathrm{p}=0.014)$ and significantly larger for the $45 \%$ protein feed $(\mathrm{p}=0.001)$, as compared to the TLs of shrimp used in field feeding trials. A significant interaction $(p=0.038)$ between shrimp TL and trial setting prevented any differences in main effects on GPT from being interpreted for the $20.1 \%$ protein feed. Even with this statistically significant interaction, Fig. 1b suggests that mean GPTs in the field and laboratory for the $20.1 \%$ protein feed were not different.

\section{Litopenaeus vannamei: feed lipid content-effect on field and laboratory GPT}

The effect of varying the feed's lipid percentage on GPTs in field and laboratory feeding trials was examined for $L$. vannamei using 5 feeds ranging from 3.5 to $13.5 \%$ lipid (Fig. 1c). Mean GPTs $( \pm \mathrm{SE})$ from the laboratory trials $(\mathrm{N}=135)$ and field trials $(\mathrm{N}=192)$ are shown in Table 4. Shrimp fed the lowest (3.5\%) lipid feed showed a significant difference in GPT between field and laboratory $(\mathrm{p}=0.023)$, with mean laboratory GPT $\sim 8$ min shorter than mean field GPT. There were no significant interactions between trial setting and shrimp TL, and GPT was not affected by differences in shrimp TL.

\section{Gut passage rates}

GPTs from all the feeds were pooled by species and by setting to determine whether feed passed through the gut at different rates for different lengths of GPT. If feed is passed through the gut at a constant rate, a linear relationship would be found between GPT and GPR, as feed would simply take proportionally more time to transit a longer gut. Instead, our data demonstrate an inverse first-order relationship between GPT and GPR for the 2 species in both the field and laboratory (Fig. 2, Table 5). This relationship is based on the position of the leading edge of feed within the shrimp gut. Although a similar relationship may exist in terms of the mass of material passed per unit time, we were unable to quantitatively collect feces.

In both feeding trial settings, GPR is more sensitive to small changes in GPT at short GPTs than at long GPTs. The rate of change of GPR for each species is similar between the field and laboratory settings (Fig. 2). Combined with the results of previous work (Stephen 2001), our results suggest that within the range of feed quality used and independent of species, shrimp display some degree of plasticity in the rate at which they pass food through their guts. We suspect that this plasticity in GPR may be related to shrimp 


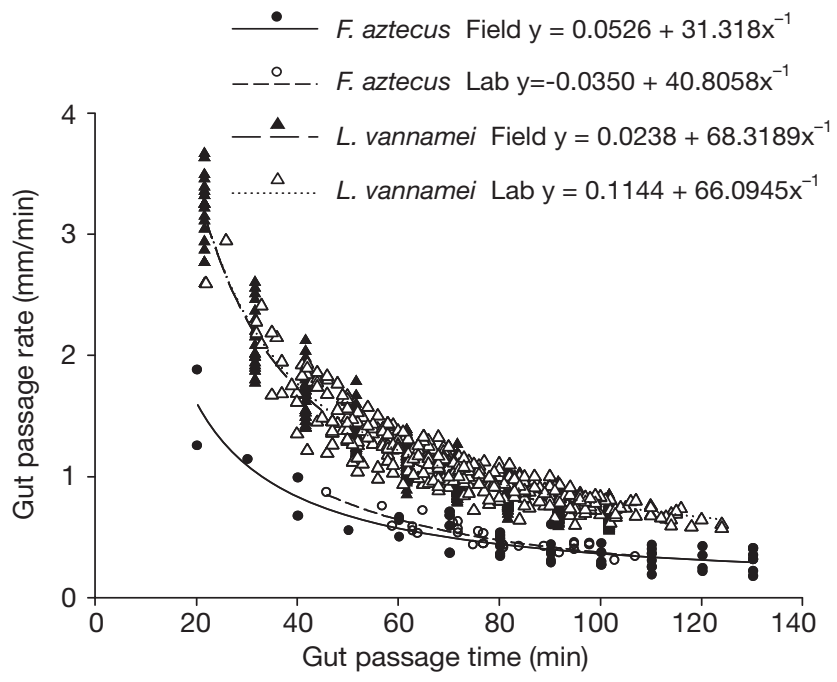

Fig. 2. Farfantepenaeus aztecus and Litopenaeus vannamei. Best-fit inverse first-order regressions of gut passage rate as a function of gut passage time. $F$. aztecus field $(\mathrm{N}=51)$ and laboratory $(\mathrm{N}=28)$ feeding trials on the base feed. $L$. vannamei field $(\mathrm{N}=727)$ and laboratory $(\mathrm{N}=355)$ feeding trials on all fiber, lipid, and protein feeds; $y=y_{0}+a x^{-1}$. Coefficients in Table 5

omnivory and the ability to consume and digest foods of widely varying nutritional quality. We plan to investigate this apparent plasticity in future feeding trials. Although one might expect GPT and shrimp TL to be positively correlated, GPR showed no significant linear correlation with shrimp TL for either species (Farfantepenaeus aztecus: $\mathrm{r}^{2}=0.2813$ laboratory, $\mathrm{r}^{2}=0.0003$ field; Litopenaeus vannamei: $\mathrm{r}^{2}=0.0016$ laboratory, $r^{2}=0.0004$ field) .

\section{DISCUSSION}

\section{Gut passage times}

This is the first study designed to compare field and laboratory GPTs for penaeid shrimp. There was no error associated with our direct measurements of GPT in the laboratory utilizing a $2 \mathrm{~h}$ starvation period. In contrast, the noise in our field methods was unavoidable - we were unable to utilize a starvation period, and our method of observing 'snapshots' of feed location in the gut at $10 \mathrm{~min}$ intervals introduces a possible overestimate of GPT by a maximum of $10 \mathrm{~min}$. Even with the addition of a 'defecation delay' and using feeds and methods different from those used by others, our GPTs reinforce previous gut clearance measurements for several other species. Although our study did not measure the time needed for complete evacuation of a meal from the gut, based on our values for GPT, we believe it is reasonable to assume that gut
Table 5. Farfantepenaeus aztecus and Litopenaeus vannamei. Inverse first-order regression coefficients for gut passage rate versus gut passage time in field and laboratory settings ( $y=$ $y_{0}+a x^{-1}$, see Fig. 2)

\begin{tabular}{|lccc|}
\hline Setting & $y_{\mathrm{o}}$ & $a$ & $\mathrm{r}^{2}$ \\
\hline F. aztecus & & & \\
Field & 0.0526 & 31.3180 & 0.8536 \\
Laboratory & -0.0350 & 40.8058 & 0.7997 \\
L. vannamei & & & \\
Field & 0.0238 & 68.3189 & 0.9436 \\
Laboratory & 0.1144 & 66.0945 & 0.8677 \\
\hline
\end{tabular}

evacuation was complete in about double the mean GPT values for each species (about $3 \mathrm{~h}$ for Farfantepenaeus aztecus, slightly less time for Litopenaeus vannamei) (Beseres et al. 2005). Nunes \& Parsons (2000b) reported that, for Penaeus subtilis, foregut evacuation was nearly compete in $2 \mathrm{~h}$ after feeding, and Cockcroft \& McLachlan (1986) measured complete evacuation of the foregut in 2 to $4 \mathrm{~h}$ for the penaeid Macropetasma africanus. Similar gut clearance times have been reported for $P$. monodon, $P$. esculentus, $P$. stylirostris, $P$. californiensis, $P$. vannamei (Dall et al. 1990), and P. semisulcatus (Heales et al. 1996).

For both Farfantepenaeus aztecus and Litopenaeus setiferus, our hypothesis that GPTs in the field would be shorter than those in the laboratory was not supported, as GPTs tended to be slightly longer in the field. One explanation for the slightly longer GPTs from the field feeding trials may be the lack of a starvation period (again, imposed upon us and unavoidable), as compared to the 2 to $3 \mathrm{~h}$ starvation period used prior to the laboratory feeding trials. Dall et al. (1990) described that starved shrimp tend to ingest food more rapidly than shrimp that have had continuous access to food. Our informal observations indicated that shrimp in the field feeding trials had natural food items in the gut at the start of the experiment. In contrast, shrimp in the laboratory trials were starved beforehand and may have been less selective than those in the field, perhaps increasing ingestion rates and reducing GPTs.

We anticipated that shrimp in field feeding trials would have faster GPTs due to the consumption of less-nutritious natural foods. Invertebrates have been shown to vary their GPTs, and GPTs have been linked to food quality (Cammen 1980, Taghon 1981). We assumed that the mixing of low-quality non-feed items, such as detritus, with the high-quality experimental feed in the gut would constitute an overall less-nutritious feed, reducing the absorption time by the gut lining. Alternatively, shrimp in the field setting may have held lower-quality food in the gut for a longer period of time, to increase the extraction of energy from food particles (Calow 1975, Relyea \& Auld 2004), thereby increasing GPTs. Taghon (1981) suggested that when 
an organism has limited selective ability among food items and a limited ability to seek new food patches, varying GPTs and ingestion rates as a function of the available food's nutritional quality may be the principal method of maximizing energy intake. Within trial settings, we did not see any consistent pattern of changes in GPT as a function of large variations in fiber, protein, or lipid content, suggesting that all the experimental feeds were of high quality.

Visual identification of 'non-feed' items inside the guts of Farfantepenaeus aztecus and Litopenaeus vannamei recovered from field enclosures confirms that shrimp consumed non-labeled items along with experimental feed. Non-feed items could not be further quantified without performing gut content analysis; exploratory investigations agree with results reported by Dall et al. (1990) that the macerated condition of penaeid gut contents makes identification of food items very difficult. In our study, once labeled feed was consumed (and observed in the shrimp gut), the percent by volume of non-feed items was usually $<5 \%$ and never $>20 \%$, perhaps suggesting that the nonfeed items were less attractive to the shrimp.

Most benthic and zooplankton prey in shrimp ponds are utilized shortly after being stocked with postlarval shrimp, leaving detritus as the main alternate food source (Nunes \& Parsons 2000a, Coman et al. 2003, Preston et al. 2003). Detritus is a low-quality food due to low nitrogen levels; animals require foods with a $\mathrm{C}: \mathrm{N}$ ratio of roughly $17: 1$ or less, whereas the $\mathrm{C}: \mathrm{N}$ ratio for detritus in salt marshes typically ranges from 20:1 to 60:1 (Valiela 1995). Detritus has a very low energy content $(0.458 \mathrm{kcal}$ $\mathrm{kg}^{-1}$ ) (Qasim 1974) as compared to reported intake energy values of 3800 and $4000 \mathrm{kcal} \mathrm{kg}^{-1}$, respectively, for 15.4 and $18.2 \%$ protein feeds (Velasco et al. 2000). Our feeds also contained about $4000 \mathrm{kcal} \mathrm{kg}^{-1}$.

Shrimp raised in culture ponds will always have access to detritus and benthic food sources. Dall et al. (1990) reported that significant quantities of plant detritus have been found in the guts of juvenile penaeids in shallow inshore areas. Investigations of the relationship between GPT and feed quality without consideration of natural food resources may be incomplete. Shrimp are omnivorous, and it is unknown whether they primarily digest non-living detrital material or if they utilize detritus-based microflora. The nutritional role of detritus, a complex of particulate matter derived from plant and animal breakdown in a matrix with diatom particles and bacteria, is difficult to assess (Robertson 1988).

Statistically speaking, our comparisons of GPTs measured for both species showed some differences between field and laboratory feeding trial settings. However, ecologically and practically speaking, even when non-feed items of different quality were observed in shrimp guts from the field setting, GPTs measured in field and laboratory feeding trials differed by just 10 to 20 min. Since our indirect field GPT determination methods only allowed us to view a 'snapshot' of feed location in the gut every $10 \mathrm{~min}$, the observed 10 to 20 min difference in GPT between the field and laboratory may be due, in part, to noise in our field methods. For shrimp pond managers, is a 10 to 20 min difference in GPT enough to warrant making a change in feeding regimes? Measurement of GPT in the field requires a great investment of time, money, and labor. In contrast, determination of GPT in the laboratory is relatively easy and can be conducted over a shorter period of time. We suggest that even a maximum difference in mean GPT of 20 min may be trivial enough to justify using estimates of GPTs in laboratory feeding trials to extrapolate reliably to field populations of the same species for design of more efficient feeding regimes.

\section{Gut passage rates}

We were surprised to find such high variability in GPRs (Fig. 2). GPRs were not correlated with shrimp size-small shrimp did not pass feed through their gut any faster than large shrimp. Morales et al. (1990) also found that the gut evacuation rate was unrelated to body size in copepods. Shrimp may make compensatory adjustments to GPR based on appetite (Bowen et al. 1995), or may adjust their feeding strategy to maximize their food absorption rate (Ahrens et al. 2001). Shrimp within the size range observed in this study may have been able to control their GPR relative to parameters that were not measured. Similar GPR results found in both laboratory and field settings in our study of 2 penaeid species also support extrapolation of feeding behavior from the laboratory to the field.

\section{Laboratory versus field measurements}

Nearly all physiological, trophic, energetic, and behavioral studies of marine organisms conducted in a laboratory setting are built on the fundamental assumption that laboratory measurements factually represent field measurements. However, when conducting laboratory experiments and extrapolating their results to the field without corresponding field measurements, this fundamental assumption is seldom tested. In this study, we observed GPTs in the laboratory which were, in a majority of cases, statistically not significantly different from field measurements ( $p>0.05$ for 9 of 13 feeds for Litopenaeus vannamei). These results were obtained despite experimental design constraints including a lack of a standardized 
prior starvation time for field animals, sampling interval errors inherent in the field GPT-determination method, and variations in feed quality in different feeding trials. Whether the 10 to 20 min difference in GPTs measured in the laboratory versus field is truly a negligible difference is subjective and depends on the desired application of these data. While quantitative ecologists and/or statisticians may view this 10 to 20 min difference as a substantial proportion of the mean GPTs measured in both settings, a shrimp farmer might not. We suggest that the differences measured are so small that laboratory estimates of GPTs alone may be used reliably to design more efficient, less wasteful feeding regimes for these penaeid species. Additional tests of the fundamental assumption are needed in a variety of other species.

Acknowledgements. This research was sponsored by the South Carolina Sea Grant Consortium pursuant to National Oceanic and Atmospheric Administration Award No. R/A-32. The authors acknowledge funding from the Slocum-Lunz Foundation and the South Carolina Wildlife Federation. Thanks to Drs. D. M. Allen, J. M. Dean, and S. E. Stancyk for their advice, and to Mr. D. Dunkelberger of Palmetto Aquaculture and Mr. and Mrs. W. Campbell for use of the shrimp ponds. We also thank S. Hagins for performing the longitudinal measurements, and L. Maliszewski, T. Fitzhenry, M. Jaskowski, F. Helies, J. Housand, K. Palmigiano, B. Gaskins, K. Fedorka, K. Bretsch, J. Pollack, and J. Stephen for help in the field. We thank 3 anonymous reviewers for their helpful contributions. This study partially fulfilled requirements of the Marine Science Program for J.J.B.'s M.S. degree program. This is Contribution No. 1416 from the Belle W. Baruch Institute for Marine and Coastal Sciences.

\section{LITERATURE CITED}

Ahrens MJ, Hertz J, Lamoureux EM, Lopez GR, McElroy AE, Brownawell BJ (2001) The effect of body size on digestive chemistry and absorption efficiencies of food and sediment-bound organic contaminants in Nereis succinea (Polychaeta). J Exp Mar Biol Ecol 263:185-209

Allan GL, Smith DM (1998) Recent nutrition research with Australian penaeids. Rev Fish Sci 6:113-127

Beseres JJ, Lawrence AL, Feller RJ (2005) Variation in fiber, protein, and lipid content of shrimp feed-effects on gut passage times measured in the field. J Shellfish Res 24: 301-308

Bollens GCR, Penry DL (2003) Feeding dynamics of Acartia spp. copepods in a large, temperate estuary (San Francisco Bay, CA). Mar Ecol Prog Ser 257:139-158

Bowen SH, Lutz EV, Ahlgren MO (1995) Dietary-protein and energy as determinants of food quality-trophic strategies compared. Ecology 76:899-907

Calow P (1975) Defecation strategies of two freshwater gastropods, Ancylus fluviatus Müll. and Planorbis contortus Linn. (Pulmonata) with a comparison of field and laboratory estimates of food absorption rate. Oecologia 20:51-63

Cammen LM (1980) Ingestion rate: an empirical model for aquatic deposit feeders and detritivores. Oecologia 44: $303-310$

Clark OM (2000) Feeding dynamics of postlarval penaeid shrimp: gut passage time, prey composition and daily ration. MS thesis, University of South Carolina, Columbia

Cockcroft A, McLachlan A (1986) Food and feeding habits of the surf zone penaeid prawn Macropetasma africanus (Balss). PSZNI Mar Ecol 7:345-357

Coman FE, Connolly RM, Preston NP (2003) Zooplankton and epibenthic fauna in shrimp ponds: factors influencing assemblage dynamics. Aquac Res 34:359-371

Dall W, Hill BJ, Rothlisberg PC, Sharples DJ (1990) The biology of the Penaeidae. Adv Mar Biol 27:1-461

Evjemo JO, Vadstein O, Olsen Y (2000) Feeding and assimilation kinetics of Artemia franciscana fed Isochrysis galbana (clone T. Iso). Mar Biol 136:1099-1109

Fair PH, Fortner AR, Millikin MR, Sick LV (1980) Effects of dietary fiber on growth, assimilation and cellulose activity of the prawn (Macrobrachium rosenbergii). Proc World Maric Soc 11:369-381

Feller RJ (1998) Estimating gut passage times: relevance for feeding regimes in cultured shrimp. In: Jory DE (ed) Proceedings of the First Latin American shrimp farming congress, 6-10 Oct 1998, Panama City. Grupo de Ferias, Congresos y Eventos, SA, p 1-7

Glencross BD, Smith DM, Thomas MR, Williams KC (2002) The effects of dietary lipid amount and fatty-acid composition on the digestibility of lipids by the prawn, Penaeus monodon. Aquaculture 205:157-169

Gregg CS, Fleeger JW (1998) Grass shrimp Palaemonetes pugio predation on sediment- and stem-dwelling meiofauna: field and laboratory experiments. Mar Ecol Prog Ser 175:77-86

Harvey M, Morrier G (2003) Laboratory feeding experiments on zoea of northern shrimp Pandalus borealis fed with natural zooplankton. Mar Ecol Prog Ser 265:165-174

Heales DS, Vance DJ, Loneragan NR (1996) Field observations of moult cycle, feeding behaviour, and diet of small juvenile tiger prawns Penaeus semisulcatus in the Embley River, Australia. Mar Ecol Prog Ser 145:43-51

Hoyt M, Fleeger JW, Siebeling R, Feller RJ (2000) Serological estimation of prey-protein gut-residence time and quantification of meal size for grass shrimp consuming meiofaunal copepods. J Exp Mar Biol Ecol 248:105-119

Kanazawa A (1997) Research in Asia. In: D'Abramo LR, Conklin DE, Akiyama DM (eds) Crustacean nutrition: advances in world aquaculture, Vol 6. World Aquaculture Society, Baton Rouge, LA, p 553-565

Koshio S, Teshima S, Kanazawa A, Watase T (1993) The effect of dietary-protein content on growth, digestion efficiency and nitrogen-excretion of juvenile Kuruma prawns, Penaeus japonicus. Aquaculture 113:101-114

Lawrence AL, Lee PG (1997) Research in the Americas. In: D'Abramo LR, Conklin DE, Akiyama DM (eds) Crustacean nutrition: advances in world aquaculture, Vol 6. World Aquaculture Society, Baton Rouge, LA, p 566-587

Lee DL (1971) Studies on the protein utilization related to growth of Penaeus monodon Fabricius. Aquaculture 1: $1-13$

Morales CE, Bautista B, Harris RP (1990) Estimates of ingestion in copepod assemblages: gut fluorescence in relation to body size. In: Barnes M, Gibson RN (eds) Trophic relationships in the marine environment. Proc 24th Eur Mar Biol Symp. Academic Press, London, p 565-577

Nunes AJP, Parsons GJ (1998) Dynamics of coastal tropical aquaculture systems and the consequences to waste production. World Aquac 29:27-37

Nunes AJP, Parsons GJ (2000a) Effects of the southern brown shrimp, Penaeus subtilis, predation and artificial feeding on the population dynamics of benthic polychaetes in 
tropical pond enclosures. Aquaculture 183:125-147

Nunes AJP, Parsons GJ (2000b) Size-related feeding and gastric evacuation measurements for the southern brown shrimp Penaeus subtilis. Aquaculture 187:133-151

Pèrez Farfante I, Kensley B (1997) Penaeid and sergestoid shrimps and prawns of the world; keys and diagnoses for the families and genera. Mem Mus Nat Hist Nat (Fr) 173: $1-233$

Preston NP, Coman FE, Fry VM (2003) Shrimp pond zooplankton dynamics and the efficiency of sampling effort. Aquac Res 34:373-381

Qasim SZ (1974) Energy conversion in the shrimp, Metapenaeus monoceros (Fabricius), fed on detritus. Indian J Mar Sci 3:131-134

Relyea RA, Auld JR (2004) Having the guts to compete: how intestinal plasticity explains the costs of inducible defences. Ecol Lett 7:869-875

Robertson AI (1988) Decomposition of mangrove leaf litter in tropical Australia. J Exp Mar Biol Ecol 116:235-247

Sedgwick RW (1979) Effect of ration size and feeding frequency on the growth and food conversion of juvenile Penaeus merguiensis de Man. Aquaculture 16:179-198

Stephen J (2001) Gut passage time, nitrogen assimilation efficiency, and growth in the white shrimp, Litopenaeus

Editorial responsibility: Kenneth $R$. Tenore (Contributing Editor), Solomons, Maryland, USA setiferus. MS thesis, University of South Carolina, Columbia

Taghon GL (1981) Beyond selection: optimal ingestion rate as a function of food value. Am Nat 118:202-214

Tiselius P, Hansen B, Jonsson P, Kiørboe T, Nielsen TG, Piontkovski S, Saiz E (1995) Can we use laboratory-reared copepods for experiments? A comparison of feeding-behavior and reproduction between a field and a laboratory population of Acartia tonsa. ICES J Mar Sci 52:369-376

Valiela I (1995) Marine ecological processes, 2nd edn. Springer-Verlag, New York

Velasco M, Lawrence AL, Castille FL, Obaldo LG (2000) Dietary protein requirement for Litopenaeus vannamei. In: Cruz-Suárez LE, Ricque-Marie D, Tapia-Salazar M, Olvera-Novoa MA, Civera-Cerecedo R (eds) Avances en nutrición acuícola V. Memorias del V simposium internacional de nutrición acuícola, 19-22 Nov 2000. Méridia, Yucatán, p 181-192

Wu L, Xie SQ, Zhu XN, Cui YB, Wootton RJ (2002) Feeding dynamics in fish experiencing cycles of food deprivation: a comparison of four species. Aquac Res 33:481-489

Wuenschel MJ, Werner RG (2004) Consumption and gut evacuation rate of laboratory-reared spotted seatrout (Sciaenidae) larvae and juveniles. J Fish Biol 65:723-743

Submitted: July 8, 2004; Accepted: September 8, 2005

Proofs received from author(s): February 9, 2006 